\title{
Commentary: Failure predicting failure: The right ventricle after left ventricular assist device implantation
}

\author{
Joanna Chikwe, MD, ${ }^{\mathrm{a}, \mathrm{b}}$ Anelechi Anyanwu, MD, ${ }^{\mathrm{a}}$ Javed Butler, $\mathrm{MD},{ }^{\mathrm{c}}$ and Allison McLarty, $\mathrm{MD}^{\mathrm{b}}$
}

\footnotetext{
From the ${ }^{\mathrm{a}}$ Department of Cardiovascular Surgery, Mount Sinai Medical Center, New York, NY; ${ }^{b}$ Department of Surgery, The State University of New York-Stony Brook, Stony Brook, NY; and ${ }^{\mathrm{c}}$ Department of Medicine, University of Mississippi, Jackson, Miss.

Disclosures: Authors have nothing to disclose with regard to commercial support.

Received for publication Dec 15, 2018; accepted for publication Dec 17, 2018; available ahead of print Jan 29, 2019

Address for reprints: Joanna Chikwe, MD, Department of Cardiovascular Surgery, Mount Sinai Medical Center, 1190 Fifth Ave, New York, NY 10029 (E-mail: Joanna.Chikwe@mountsinai.org).

J Thorac Cardiovasc Surg 2019;157:1861-2

$0022-5223 / \$ 36.00$

Copyright (C) 2018 Published by Elsevier Inc. on behalf of The American Association for Thoracic Surgery

https://doi.org/10.1016/j.jtcvs.2018.12.057
}

Right ventricular failure limits the effectiveness of left ventricular assist device (LVAD) implantation and is associated with increased operative mortality, multiorgan failure, worse long-term survival, and poorer functional status. There is no definitive treatment, and although early placement of right ventricular assist devices (RVADs) can reduce early mortality, they do not eliminate the negative prognostic influence of post-LVAD right heart failure. Recent analysis of 9976 LVAD implants from the Interagency Registry for Mechanically Assisted Circulatory Support showed $56 \%$ 1-year survival in patients who needed RVADs within 2 weeks of an LVAD, compared with $82 \%$ in patients without RVADs. ${ }^{1}$ The focus has been on preoperatively identifying patients at risk of right ventricular failure in the hope that intensified medical treatment, or early RVAD use, could improve outcomes. At least 10 predictive models have been designed with this aim, utilizing clinical, laboratory, hemodynamic, and echocardiographic parameters, but all have poor predictive values in independent datasets. $^{2,3}$ Tang and colleagues ${ }^{4}$ take a new approach, using cluster analysis to identify groups of patients at high risk for right heart failure among 490 patients undergoing durable LVAD implantation at their institution. Confirming previous studies, they report that preoperative severe right ventricular dysfunction predicts post-LVAD right ventricular failure, and severe tricuspid regurgitation preoperatively is associated with twice the likelihood of postoperative right ventricular failure compared with patients with moderate or lesser tricuspid regurgitation.

Despite these insights, a robust predictive model for right heart failure after LVAD implantation remains elusive for several reasons. Firstly, many risk factors for right ventricular failure cannot be measured accurately. For example, predictive laboratory data such as liver function tests are insufficiently discriminatory. Secondly, procedure-related factors-such as acidosis, hypoxia, hypercarbia, air emboli, blood transfusions, volume

\section{References}

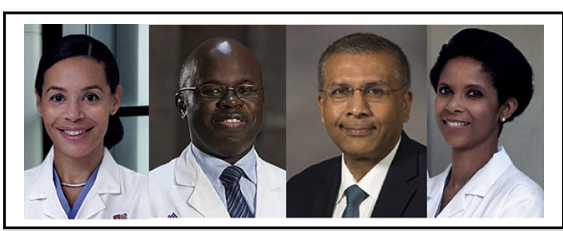

Joanna Chikwe, MD, Anelechi Anyanwu, MD, FRCS, Javed Butler, MD, and Allison McLarty, MD

Central Message

Retrospective studies fail to generate reliable predictive models for post-LVAD right heart failure. Prospective studies are needed.

See Article page 1851.

overload, prolonged cardiopulmonary bypass, and ischemic injury-interact with and amplify preoperative risk factors. Consequently, patients after uncomplicated LVAD implantation have a very different risk of right heart failure compared with those who experience surgery complicated by hypoxia and massive transfusion. Thirdly, current predictive models are primarily based on variables obtained from retrospective chart reviews, with limited discrimination of severity, etiology, or reversibility of right ventricular dysfunction. ${ }^{2}$ Strain imaging to assess subclinical functional abnormalities is not as established as for the left ventricle nor is the expertise widely available. Finally, right ventricular function is dynamic, dependent on volume and pressure loading. Accurate evaluation is complicated by tricuspid regurgitation, itself a highly dynamic, load-dependent lesion that may be a cause or a sequela of right ventricular dysfunction and may mask its severity. How preload, afterload, and the tricuspid valve are managed influences both the severity and effects of right ventricular failure post-LVAD.

Predictive scores remain research tools that help us understand the epidemiology of right heart failure. Designing risk models that contribute meaningfully to clinical decision making will require prospective studies. ${ }^{5}$ The variable and complex interaction among patients, physicians, operative (procedure related), and institutional factors means that robust prediction will likely remain impractical, but Tang and colleagues ${ }^{4}$ deserve credit for their substantial contributions to this challenge.

1. Kiernan MS, Grandin EW, Brinkley M, Kapur NK, Pham DT, Ruthazer R, et al Early right ventricular assist device use in patients undergoing continuous-flow 
left ventricular assist device implantation: incidence and risk factors from the interagency registry for mechanically assisted circulatory support. Circ Heart Fail. 2017;10.

2. Hayek S, Sims DB, Markham DW, Butler J, Kalogeropoulos AP. Assessment of right ventricular function in left ventricular assist device candidates. Circ Cardiovasc Imaging. 2014:7:379-89.

3. Kalegorpoulos AP, Siwamogsatham S, Weinberger JF, Kelkar AA, Georgiopoulou VV, Pekarek A, et al. Clinical scores and echocardiography for right ventricular risk prediction after implantation of continuous-flow left ventricular assist devices. J Heart Lung Transplant. 2013;32:S273.

4. Tang PC, Haft JW, Romano MA, Bittar A, Hasan R, Palardy M, et al. Cluster analysis of preoperative echocardiographic findings and outcomes following left ventricular device implantation. J Thorac Cardiovasc Surg. 2019;157:1851-60.e1.

5. Kalogeropoulos AP, Al-Anbari R, Pekarek A, Wittersheim K, Pernetz MA, Hampton A, et al. The right ventricular function after left ventricular assist device (RVF-LVAD) study rationale and preliminary results. Eur Heart J Cardiovasc Imag. 2016;14:429-37. 